\title{
Incidence and trends of low back pain hospitalisation during military service - An analysis of 387,070 Finnish young males

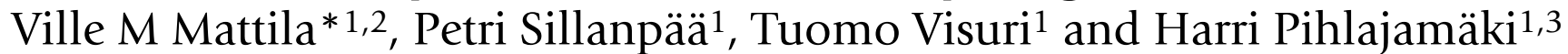

\author{
Address: ${ }^{1}$ Centre for Military Medicine, Lahti and Helsinki, P.O.Box 50, 00301 Helsinki, Finland, ${ }^{2}$ Hämeenlinna Central Hospital, Hämeenlinna, \\ Finland and ${ }^{3}$ Department of Medical Services, Defence Staff, Finnish Defence Forces, P.O.Box 50, 00301 Helsinki, Finland \\ Email: Ville M Mattila* - ville.mattila@uta.fi; Petri Sillanpää - petri.sillanpaa@uta.fi; Tuomo Visuri - tuomo.visuri@helsinki.fi; \\ Harri Pihlajamäki - harri.pihlajamaki@helsinki.fi \\ * Corresponding author
}

Published: 19 January 2009

BMC Musculoskeletal Disorders 2009, 10:10 doi:10.1 186/147|-2474-10-10
Received: 17 September 2008

Accepted: 19 January 2009

This article is available from: http://www.biomedcentral.com/I47/-2474/I0/10

(C) 2009 Mattila et al; licensee BioMed Central Ltd.

This is an Open Access article distributed under the terms of the Creative Commons Attribution License (http://creativecommons.org/licenses/by/2.0), which permits unrestricted use, distribution, and reproduction in any medium, provided the original work is properly cited.

\begin{abstract}
Background: There is evidence that low back pain (LBP) during young adulthood and military service predicts LBP later in life. The purpose of this study was to investigate the incidence and trends of LBP hospitalisation among Finnish military conscripts.

Methods: All male conscripts performing their compulsory military service during 1990-2002 were included in the study population. Altogether 387,070 military conscripts were followed throughout their six-to-twelve-month service period. Data on LBP hospitalisations were obtained from the National Hospital Discharge Register.

Results: Altogether 7,240 LBP hospitalisations were identified among 5,06I (I.3\%) male conscripts during the study period. The event-based incidence of LBP hospitalisation was 27.0 ( $95 \%$ confidence interval (Cl): 25.7-28.2). In most cases, the diagnosis was unspecified LBP $(n=5,141,71 \%)$ followed by lumbar disc disorders $(n=2,069,29 \%)$. Hospitalisation incidence due to unspecified LBP was 19.1 per I,000 person-years ( $95 \% \mathrm{Cl}$ : 18.3 to 20.4 ), and 7.8 per I,000 person-years ( $95 \% \mathrm{Cl}: 6.7$ to 8.3) due to lumbar disc disorders. The incidence of unspecified LBP remained unaltered, while hospitalisation due to lumbar disc disorders declined from 1993 onwards.
\end{abstract}

Conclusion: Although conscripts accepted into military training pass physician-performed examinations as healthy, young adults, LBP hospitalisation causes significant morbidity during military service.

\section{Background}

High prevalence rates of low back pain (LBP) have been reported among working-age populations $[1,2]$. The prevalence of LBP is highest in middle age, but an increasing occurrence has been observed among adolescents and young adult populations [3-6]. It has been estimated that by the age of 20 approximately fifty percent of people have suffered from LBP at least once [7], while the prevalence of sciatic pain has varied between $1.8 \%$ [8] and $4 \%$
[9]. There is evidence that LBP during young adulthood and military service predicts LBP later in life [10], and may lead to chronic disability $[1,2]$. Although LBP has been studied widely in active duty soldiers, and estimated to cause a loss of billions of dollars annually in the United States [11], morbidity and incidence of LBP hospitalisations have not been described in military conscript populations. 
The increasing prevalence of overweight and obesity and the overall trend of declining physical activity among adolescents and young adults have raised substantial concerns in developed countries $[12,13]$. A previous study by Santtila et al. [12] from Finland showed a significant deterioration in physical fitness and, simultaneously, an increase in body weight among Finnish conscripts during the past three decades. An interesting question is how these changes affect the prevalence of LBP. Based on existing knowledge, the association between overweight and LBP among adolescents and young adults is weak [14-17], but overweight is associated with clinically defined sciatica [18]. Similarly, the association between physical activity and LBP has emerged as a controversial issue, since both high [17,19-21] and low levels [22,23] of physical activity have been identified as risk factors for LBP. In addition, a recent review article found no evidence of association between LBP and physical capacity [24].

Military service in Finland is compulsory for all male citizens above 18 years of age, and over $80 \%$ of men complete their service period, duration varying from 6 to 12 months. Military service begins with a 9-week basic training period, the content of which is basically the same for all conscripts. The special characteristics of military training include both the intensity and, since one of the main goals of the training is to improve conscripts' physical performance levels, the volume of physical activity which increases linearly during conscription. Due to the obligatory entry to military service in Finland, the epidemiological figures can be quite well generalisable to the young adult male population when mixed study settings involving sports-related or active duty soldiers are avoided.

Given the fact that during military service all conscripts have to use the services of military hospitals, the aims of the present study were to investigate the incidence, nature and secular trends of LBP hospitalisation among Finnish male conscripts during physically strenuous military service in 1990-2002 using the database of the National Hospital Discharge Register (NHDR).

\section{Methods}

study population

During the first five study years, 1990-1994, military service duration was 9 or 11 months and the starting interval was five months. Since 1995, the length of the compulsory military service period has been 6,9 , or 12 months, and a new batch of conscripts enters twice a year, in January and July (Table 1.). Service duration depends on the assigned position: those being trained to be officers, noncommissioned officers, or specialists for highly demanding duties serve for 12 months, those trained for duties requiring expert skills serve for nine months, and those trained for other rank and file serve for six months. Since 1995 , when voluntary military service was made available to female citizens, approximately $1-2 \%$ of the conscripts have been women. However, due to the small proportion of females in the military service, women were excluded from the analysis. In general, military service is performed at the age of 19-20, but earlier (18 years) or later (up to 29 years) entry is possible in special cases due to voluntary recruitment or deferment. Annually, approximately 23,000-32,000 conscripts start their service. The total number of conscripts who entered into military service during the study period 1990-2002 was 387,070 conscripts (women excluded). Given that the length of the military service varies between six and 12 months, the total exposure-time during the study period between 1990 and 2002 was 267,700 person-years. The average age of the conscripts was 20 (range 18 to 29) years, average length $178 \mathrm{~cm}$, and average weight $72 \mathrm{~kg}$, yielding a body mass index (BMI) of $23.2 \mathrm{~kg} / \mathrm{m}^{2}$.

Military training begins with a two-month basic training period consisting of 135 hours of varying physical training (17 hours per week), including marching, cycling, drill training, combat training, or other training involving heavy physical loading. During combat training and marching, every conscript usually carries approximately $26 \mathrm{~kg}$ (in summer) or $36 \mathrm{~kg}$ (in winter) of personal military equipment and, occasionally, an additional $5 \mathrm{~kg}$ to 20 $\mathrm{kg}$ of team military equipment. In addition, conscripts perform 56 hours (7 hours per week) of other physical exercises such as jogging, team sports or circuit training. After the basic training period, the amount of moderate and high-intensity physical training is slightly reduced (to 15 hours per week).

\section{low back pain hospitalisation data}

LBP hospitalisation data were obtained from the statutory, computer-based National Hospital Discharge Register of Finland (NHDR), which included information on all military conscripts admitted alive to military hospitals as inpatients for the treatment of LBP from January 1 st, 1990 to December 31 st, 2002. The main outcome varia-

Table I: Changes in coding system and duration of military service during the study period in 1990-2002.

\begin{tabular}{ll}
\hline Change & year \\
\hline ICD-coding system & 1996 \\
Duration of service from 9 and II months to 6, 9 or 12 months & 1995 \\
\hline
\end{tabular}


bles were defined as patients hospitalised with the main diagnosis of 1) lumbar and other intervertebral disc disorders with radiculopathy (lumbar disc disorder), and 2) unspecified LBP. The diagnosis in the National Hospital Discharge Register had been coded using the 9th (19901995) and 10th (1996-2001) revisions of the International Classification of Diseases (ICD) [25]. LBP hospitalisation was defined in the ICD-10 by codes M51.1 (lumbar and other intervertebral disc disorders with radiculopathy), M54.5 (low back pain), and M54.9 (dorsalgia), and in the ICD-9 by codes 7227C, 3539X, 7242A, $7245 \mathrm{~A}$, and 7249X, respectively (Table 1.). For analysis, the diagnoses were further categorised into lumbar disc disorders and unspecified LBP. All persons who started their military service during the study period, regardless of whether they served full term or not, were included in the study. During military service, all conscripts are obligated to use the medical services provided by military hospitals. In case of an emergency visit to a civilian hospital, conscripts are promptly transferred to a military hospital. Approval to use the hospitalisation data was obtained from the Institutional Review Board of the Ministry of Social Affairs and Health.

\section{statistical analysis}

This study was based on register data utilising Finland's system of national identification (ID) numbers. All Finnish citizens are assigned a personal ID-number, which, after approval by the appropriate authority and ethical committee, may be used in scientific research. SPSS 14.0.1 for Windows software was used for the statistical analysis. We calculated the event-based occurrence of LBP hospitalisation by dividing the number of LBP hospitalisations by exposure-time. Incidence and incidence rate-ratio were calculated with 95\% confidence intervals (CI). The length of the skewed hospitalisation period was compared between groups using the Mann-Whitney $U$-test.

\section{Results}

During the study period, altogether 7,240 LBP hospitalisations were identified among 5,061 conscripts, the total exposure-time being 267,700 person-years. The proportion of conscripts hospitalised during military service due to LBP was $1.3 \%$. The event-based incidence of LBP hospitalisation was 27.0 (95\% CI: 25.7-28.2) per 1,000 person-years. In most cases, the diagnosis was unspecified LBP $(n=5,141,71 \%)$ followed by lumbar disc disorders ( $n=2,069,29 \%)$. The incidence of hospitalisation due to unspecified LBP was 19.1 per 1,000 person-years (95\% CI: 18.3 to 20.4), and the incidence of hospitalisation due to lumbar disc disorder was 7.8 per 1,000 person-years (95\% CI: 6.7 to 8.3). The overall median length of hospital stay was three (range 1 to 114) days. In conscripts hospitalised due to lumbar disc disorder, the median length of hospital stay was four days compared to three days in those with unspecified LBP $(P<0.001)$. Multiple LBP hospitalisations occurred in 1,113 (22\%) conscripts, the maximum number of hospitalisations being 10 during the military service.

\section{incidence trends}

Figure 1 and 2 show the incidence of lumbar disc disease and unspecified LBP hospitalisations in Finnish conscripts in 1990-2002. The annual number of LBP hospitalisations varied between 366 (in 2002) and 728 (in 1993). Lumbar disc disorders constituted 30\% of all LBPrelated hospitalisations during the whole 13 -year study period. The highest incidence of LBP hospitalisation, 32.2 per 1,000 person-years (95\% CI: 29.6-35.3), was seen from 1991 to 1993 , and the lowest incidence, 18.9 per 1,000 person-years (95\% CI: 17.2-22.1), was seen in 2002. The incidence of hospitalisations due to unspecified LBP did not vary significantly during the study period, being 18.6 per 1,000 person-years (95\% CI: 17.3-20.4). A decline in the incidence of hospitalisations due to lumbar disc disorders was found, from $12.3 / 1,000$ person-years (highest) in 1993 (95\% CI: 9.6-13.3) to 4.2/1,000 person-years (lowest) in 2001 (95\% CI: 3.0-5.0), yielding a relative risk ratio of 0.4 (95\% CI: 0.3-0.5).

\section{Discussion}

The principal finding of the present study was that $1.3 \%$ of our male conscript study population were hospitalised for LBP during their mandatory military service. The incidence of LBP hospitalisation was 27 per 1,000 personyears and a decline in the incidence of hospitalisation due to lumbar disc disorders was found from 1993 onwards. In most cases, hospitalisation was due to unspecified LBP, while lumbar disc disorders accounted for one third of the hospitalisations. LBP causes significant morbidity during conscription. Military service training involving highintensity physical activity and higher spinal load offers unique opportunities to identify persons with a proneness to LBP.

Our study has notable strengths. The population at risk consisted of a significant number of individuals obliged to use the medical services provided by the Finnish Defence Forces for the management of LBP. Further, all conscripts had passed two, physician-performed medical examinations when entering military service, on which occasion all patients with severe back diseases, such as significant scoliosis or other congenital back anomalies, severe post-traumatic disorders, rheumatoid arthritis, or ankylosing spondylitis were exempted from duty. With good reason, conscripts meeting all medical requirements can be considered healthy young men. In addition, the accuracy and extensiveness of the NHDR database [26-28] have been shown to be excellent. The accuracy of the incidence figures for conscripts' LBP hospitalisations is supe- 


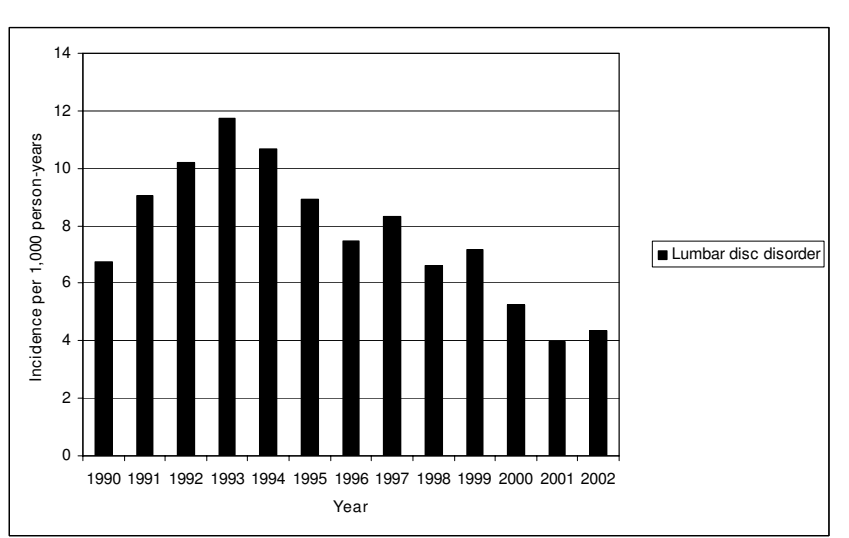

Figure I

Incidence of hospitalisation for lumbar disc disorder in Finnish conscripts in 1990-2002.

rior to that of any civil hospital registers, as the cohort included in this study had no alternative choices such as private clinics to attend due to LPB. Moreover, the authors conclude that the results are very well generalisable to a young healthy male population owing to the compulsory nature of the Finnish military service.

This study has also some weaknesses. Unfortunately, we had no means to identify less severe LBP episodes because of a lack of computer-based outpatient registers for the early 1990s. In addition, due to our relatively long followup period, some changes seen in the incidence of LBP hospitalisation may have been caused by changes in hospitalisation policies and not by true variation in the incidence. Although the emphasis in LBP management has shifted towards more active treatment regimen in Finland, this explanation is not presumable, because no changes in the incidence of unspecified LBP were seen.

The proportion of conscripts with LBP hospitalisation $(1.3 \%)$ may be considered significant for several reasons: the healthy young men comprising our study sample represented $80 \%$ of the age group, had passed two medical examinations and successfully met the health requirements set for military service. The incidence of LBP hospitalisation seen in the present study is higher than in previous publications performed in population-based study settings [9]. The hospitalisation rates among conscripts may not be directly comparable to those among recruits or civilians. All conscripts have free health care and obligation to use military hospitals, and thus the threshold of hospitalisation may be somewhat lower in military service than elsewhere. In other words, if a conscript with LBP is not able to stay in garrison despite normal non-steroidal anti-inflammatory drug treatment, he is hospitalised. Another possible explanation to increased hospitalisation rates compared to civilian populations may be the increased levels of physical exercise and lifting. The increased spinal load and the mechanical load on the intervertebral discs may cause lumbar disc herniation. Other mechanisms may include muscle tightness and loss of flexibility resulting in decreased lumbar flexion, which again has shown to be associated with LBP in athletes [29] and in military conscripts [30] too. Another explanation may be the increase in injury rates during military service [31], which may predispose to LBP [19]. A point worth noting is that despite the increasing trend of obesity and deterioration in physical fitness during the study period, no simultaneous increase in LBP hospitalisations was seen. One fifth of the conscripts had more than one LBPrelated hospitalisation during the study period. Although we had no opportunity to follow these persons after completion of military service, we may suggest that they have an increased risk of long-term morbidity caused by LBP. Prevention measures should hence be targeted at conscripts with several LBP hospitalisations during their military service.

A notable finding in the present study was the decline in the incidence of LBP hospitalisation during the study period, which was attributed to a reduction in hospitalisations due to lumbar disc disorders. As the decline started in 1993, before the ICD-9 was superseded by the ICD-10 coding system in 1995, this change is not a viable explanation. Changes in military training or equipment do not explain this decline either. Because population-based information on the prevalence of lumbar disc disorders is not available for this period, the authors cannot conclude if the phenomenon results from a real change in the incidence or perhaps from changes in hospitalisation policies. A reduction in the frequency of hospitalisations due to lumbar disc disorders is supported by the findings from a recent Finnish report, in which the overall decline in lumbar disc surgeries amounted to 27\% from 1995 to 2005 with simultaneous reduction in the number of hospitalisation days by $13 \%$ [32]. The tendency towards more active mobilisation after lumbar disc disorders may in turn partly explain the decline in the overall hospitalisation incidence. However, a significantly longer hospital stay (four vs. three days) was observed due to lumbar disc disorders than due to unspecified LBP.

\section{Conclusion}

Our study sample comprised 391,241 military conscripts representing $80 \%$ of a given age group of healthy Finnish males. The incidence of LBP hospitalisation due to lumbar disc disorders underwent a decrease from 1993 onwards. In most cases, hospitalisation was due to unspecified LBP, while lumbar disc disorders accounted for one third of the hospitalisations. Although military conscripts are healthy, physically active young adults, LBP 


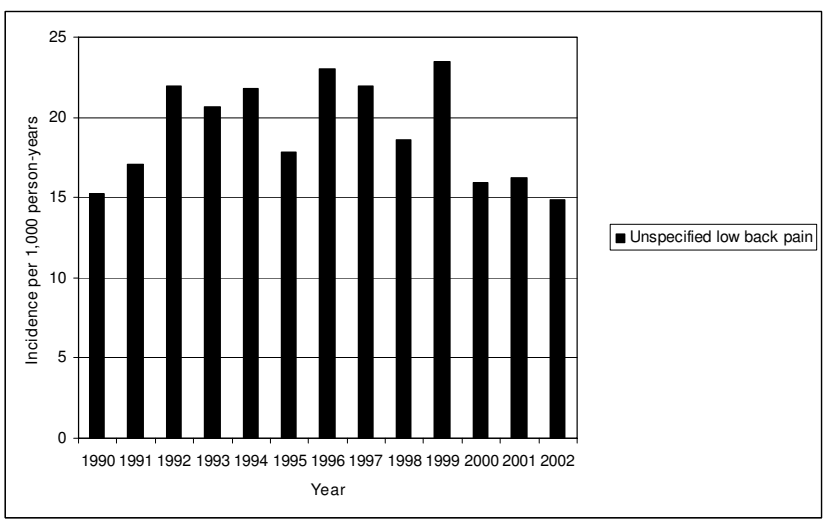

Figure 2

Incidence of hospitalisation for unspecified low back pain in Finnish conscripts in 1990-2002.

causes significant morbidity in this population. Military service environment offers unique opportunities to prevent morbidity caused by LBP.

\section{Competing interests}

The authors declare that they have no competing interests.

\section{Authors' contributions}

VM drafted the manuscript and performed statistical analysis. PS, TV and HP designed the study. HP conceived of the study, and participated in its design and coordination and helped to draft the manuscript. All authors read and approved the final manuscript.

\section{Acknowledgements}

We thank Marja Vajaranta for language editing.

\section{References}

I. Kaaria S, Kaila-Kangas L, Kirjonen J, Riihimaki H, Luukkonen R, LeinoArjas P: Low back pain, work absenteeism, chronic back disorders, and clinical findings in the low back as predictors of hospitalization due to low back disorders: a 28-year followup of industrial employees. Spine 2005, 30:|2||-|2|8.

2. Kaaria S, Luukkonen R, Riihimaki H, Kirjonen J, Leino-Arjas P: Persistence of low back pain reporting among a cohort of employees in a metal corporation: a study with 5-, 10-, and 28-year follow-ups. Pain 2006, I 20: |3|-|37.

3. Taimela S, Kujala UM, Salminen Jj, Viljanen T: The prevalence of low back pain among children and adolescents. A nationwide, cohort-based questionnaire survey in Finland. Spine 1997, 22: II32-II36.

4. Hestbaek L, Leboeuf-Yde C, Kyvik KO, Manniche C: The course of low back pain from adolescence to adulthood: eight-year follow-up of 9600 twins. Spine 2006, 31:468-472.

5. Hakala P, Rimpela A, Salminen JJ, Virtanen SM, Rimpela M: Back, neck, and shoulder pain in Finnish adolescents: national cross sectional surveys. BMJ 2002, 325:743.

6. Petersen S, Brulin C, Bergstrom E: Recurrent pain symptoms in young schoolchildren are often multiple. Pain 2006, |2 I: I 45-I50.

7. Leboeuf-Yde C, Kyvik KO: At what age does low back pain become a common problem? A study of 29,424 individuals aged I 2-4I years. Spine 1998, 23:228-234.
8. Salminen JJ, Pentti J, Terho P: Low back pain and disability in I4year-old schoolchildren. Acta Paediatr 1992, 81:1035-1039.

9. Zitting $\mathrm{P}$, Rantakallio $\mathrm{P}$, Vanharanta $\mathrm{H}$ : Cumulative incidence of lumbar disc diseases leading to hospitalization up to the age of 28 years. Spine 1998, 23:2337-2343.

10. Hellsing AL, Bryngelsson IL: Predictors of musculoskeletal pain in men: A twenty-year follow-up from examination at enlistment. Spine 2000, 25:3080-3086.

II. Songer TJ, LaPorte RE: Disabilities due to injury in the military. American Journal of Preventive Medicine 2000, 18:33-40.

12. Santtila M, Kyrolainen H, Vasankari T, Tiainen S, Palvalin K, Hakkinen A, Hakkinen K: Physical fitness profiles in young Finnish men during the years 1975-2004. Med Sci Sports Exerc 2006, 38:1990-1994.

13. Kautiainen S, Rimpela A, Vikat A, Virtanen SM: Secular trends in overweight and obesity among Finnish adolescents in 19771999. International Journal of Obesity \& Related Metabolic Disorders 2002, 26:544-552.

14. Salminen JJ, Erkintalo M, Laine M, Pentti J: Low back pain in the young. A prospective three-year follow-up study of subjects with and without low back pain. Spine 1995, 20:2 101-2107.

15. Nissinen M, Heliovaara M, Seitsamo J, Alaranta H, Poussa M: Anthropometric measurements and the incidence of low back pain in a cohort of pubertal children. Spine 1994, 19:1367-1370.

16. Masset DF, Piette AG, Malchaire JB: Relation between functional characteristics of the trunk and the occurrence of low back pain. Associated risk factors. Spine 1998, 23:359-365.

17. Mattila VM, Saarni L, Parkkari J, Koivusilta L, Rimpela A: Predictors of low back pain hospitalization-a prospective follow-up of 57,408 adolescents. Pain 2008, 139:209-217.

18. Shiri R, Karppinen J, Leino-Arjas P, Solovieva S, Varonen H, Kalso E, Ukkola O, Viikari-Juntura E: Cardiovascular and lifestyle risk factors in lumbar radicular pain or clinically defined sciatica: a systematic review. Eur Spine / 2007, 16:2043-2054.

19. Kujala UM, Taimela S, Erkintalo M, Salminen JJ, Kaprio J: Low-back pain in adolescent athletes. Med Sci Sports Exerc 1996, 28: $165-170$.

20. Salminen JJ, Oksanen A, Maki P, Pentti J, Kujala UM: Leisure time physical activity in the young. Correlation with low-back pain, spinal mobility and trunk muscle strength in I5-yearold school children. Int J Sports Med 1993, 14:406-4I0.

21. Kovacs FM, Gestoso M, Gil del Real MT, Lopez J, Mufraggi N, Mendez Jl: Risk factors for non-specific low back pain in schoolchildren and their parents: a population based study. Pain 2003, 103:259-268.

22. Balague F, Troussier B, Salminen JJ: Non-specific low back pain in children and adolescents: risk factors. Eur Spine J 1999, 8:429-438.

23. Burton AK, Clarke RD, McClune TD, Tillotson KM: The natural history of low back pain in adolescents. Spine 1996, 21:2323-2328.

24. Hamberg-van Reenen HH, Ariens GA, Blatter BM, van Mechelen W, Bongers PM: A systematic review of the relation between physical capacity and future low back and neck/shoulder pain. Pain 2007, 130:93-107.

25. International Statistical Classification of Diseases and Related Health Problems, Tenth Revision. In Book International Statistical Classification of Diseases and Related Health Problems, Tenth Revision World Health Organization; Geneva; 1994.

26. Keskimaki I, Aro S: Accuracy of data on diagnosis, procedures and accidents in the Finnish Hospital Discharge Register. International Journal of Health Sciences 1991, 2:15-21.

27. Salmela R, Koistinen V: Is the discharge register of general hospitals complete and reliable? [in Finnish]. Sairaala 1987, 49:480-482.

28. Mattila VM, Sillanpaa P, livonen T, Parkkari J, Kannus P, Pihlajamaki H: Coverage and accuracy of diagnosis of cruciate ligament injury in the Finnish National Hospital Discharge Register. Injury 2008.

29. Kujala UM, Taimela S, Oksanen A, Salminen JJ: Lumbar mobility and low back pain during adolescence. A longitudinal threeyear follow-up study in athletes and controls. Am J Sports Med 1997, 25:363-368.

30. Ulaska J, Visuri T, Pulkkinen P, Pekkarinen H: Impact of chronic low back pain on military service. Mil Med 200I, 166:607-6II. 
31. Mattila VM, Parkkari J, Korpela H, Pihlajamaki H: Hospitalisation for injuries among Finnish conscripts in 1990-1999. Accid Anal Prev 2006, 38:99-104.

32. Pohjolainen T, Seitsalo S, Sund R, Kautiainen H: [In Process Citation]. Duodecim 2007, I23:2110-2115.

\section{Pre-publication history}

The pre-publication history for this paper can be accessed here:

http://www.biomedcentral.com/1471-2474/10/10/pre pub

Publish with Bio Med Central and every scientist can read your work free of charge

"BioMed Central will be the most significant development for disseminating the results of biomedical research in our lifetime. " Sir Paul Nurse, Cancer Research UK

Your research papers will be:

- available free of charge to the entire biomedical community

- peer reviewed and published immediately upon acceptance

- cited in PubMed and archived on PubMed Central

- yours - you keep the copyright

Submit your manuscript here:

http://www.biomedcentral.com/info/publishing_adv.asp 